H I G H L I G H T S

\section{Pathogens mind out!}

To establish infections, microbial pathogens bind to host extracellular matrix (ECM) components and colonize the host. However, according to a recent paper in Nature Immunology, the secreted ECM protein mindin (spondin 2), can also act as a patternrecognition molecule and is crucial for the initiation of innate immune responses against invaders.

Although previous work has implied that ECM macromolecules might be actively involved in immune defence against microorganisms, this is the first time the role of individual components has been explored. He et al. first cloned mouse Spon2, which encodes mindin, by differential gene expression, and, having established that this gene is highly expressed in lymphoid tissues, generated mindindeficient mice to investigate the role of this protein in immunity.

The immune system of mindindeficient mice developed normally, but when the authors tested the response of mindin-deficient mice to lipopolysaccharide (LPS), a component of the cell walls of Gramnegative bacteria, they found that these mice were resistant to LPS, unlike wild-type mice, which all died from LPS-induced septic shock. In wild-type mice, macrophages rapidly produce inflammatory cytokines after exposure to LPS; however, this did not occur in the knockout mice, indicating that mindin is essential for this response. In addition, mindin-deficient macrophages failed to respond to a range of stimuli from Gram-positive and Gram-negative bacteria.

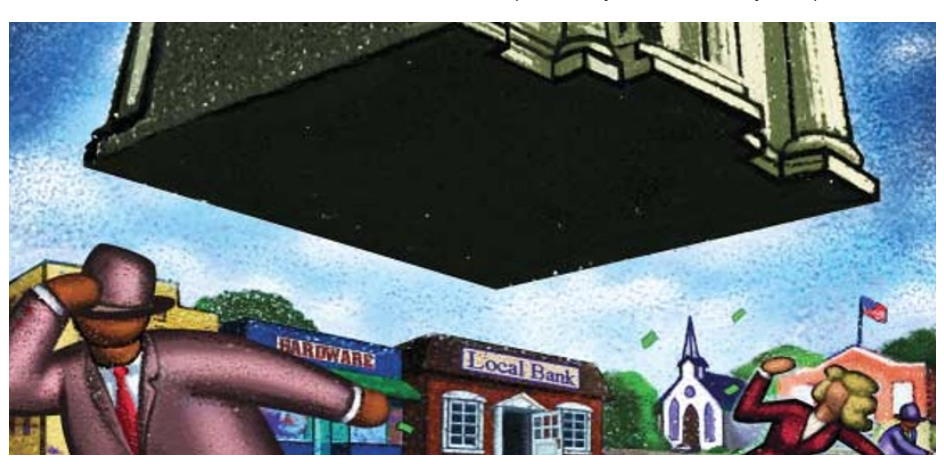

What effect does the lack of mindin have on immune responses to bacteria? Mindin-deficient mice failed to clear Haemophilus influenzae, but not Pseudomonas aeruginosa, from the lungs, highlighting a role for mindin in the pulmonary clearance of some, but not all, bacterial pathogens. Mindin-deficient mice were also shown to be more sensitive to systemic infection with Streptococcus pneumoniae, but less sensitive to Salmonella enterica serovar Typhimurium than wild-type mice.

These results indicate that mindin interacts with microbial pathogens and acts as a patternrecognition molecule for immune cells. Finally, the authors confirmed this by showing that mindin can bind directly to both Gram-negative and Gram-positive bacteria, and can also act as an opsonin for macrophage phagocytosis of some pathogens.

So, mindin is essential for the initiation of innate immune responses against bacterial pathogens, and represents a pattern-recognition molecule resident in the ECM, ready and waiting for bacterial invasion.

$$
\begin{array}{r}
\text { Jenny Buckland } \\
\text { Senior Editor, } \\
\text { Nature Reviews Immunology }
\end{array}
$$

(1) References and links ORIGINAL RESEARCH PAPER He, Y.-W. et al. The extracellular matrix protein mindin is a pattern recognition molecule for microbial pathogens. Nature Immunol. (14 Dec 2003) doi:10.1038/ni1021

\section{WEB SITES}

Michael Bevan's laboratory: http://depts. washington.edu/immunweb/faculty/ profiles/bevan.html

You-Wen He's laboratory:

\section{IN BRIEF}

\author{
VACCINES
}

Ebola virus-like particles protect from lethal Ebola virus infection

Warfield, K. L. et al. Proc. Natt Acad. Sci. USA 100, 15889-15894 (2003)

The high mortality rate and the fact that infection is spread by the aerosol route, mean that Ebola virus, a biosafety level 4 pathogen, is a potential biowarfare agent. Warfield et al. have produced Ebola virus-like particles (eVLPs) by transfecting mammalian cells with plasmids expressing the Ebola glycoprotein (GP) and matrix protein (VP40), and now report on their progress. Not only are eVLPs highly immunogenic in vitro and in VLP-vaccinated mice, they also protected mice against challenge with murine-adapted Ebola, and are therefore promising alternative vaccine candidates.

\section{GENOMICS}

\section{Reductive evolution suggested from the complete} genome sequence of a plant-pathogenic phytoplasma

Oshima, K. et al. Nature Genetics (1 Jan 2004) doi: 10.1038/ng1277

The phytoplasma species Candidatus Phytoplasma asteris, OY strain is the first obligate intracellular plant parasite and the fifth plant pathogen to be completely sequenced. Members of the Phytoplasma genus replicate in the nutrient-rich phloem and lack genes encoding the pentose-phosphate cycle and even ATP synthase. Multiple genes encoding transporters mean that this parasite can import metabolites from the plant. Coupled with a paucity of virulence factors, it seems that the pathogenic effects of this Phytoplasma strain could be caused by scavenging from the host.

\section{TECHNIQUES \& APPLICATIONS}

\section{Overcoming the hypoxic barrier to radiation therapy with anaerobic bacteria}

Bettegowda, C. et al. Proc. Nat/ Acad. Sci. USA 100, 15083-15088 (2003)

The existence of hypoxic regions within tumours is a main cause of failure for radiation therapy, one of the most common cancer treatments. Bettegowda et al. show that the obligate anaerobe Clostridium novyi-NT substantially improves the outcome of three radiotherapeutic regimens used to treat transplanted tumours in mice. C. novyi-NT acts as a radioenhancing agent by specifically targeting cells within the hypoxic areas of tumours.

\section{CLINICAL MICROBIOLOGY}

Genetic analysis of a high-level vancomycin-resistant isolate of Staphylococcus aureus

Weigel, L. M. et al. Science 302, 1569-1571 (2003)

This report presents the genetic analysis of a high-level (MIC 1,024 $\mu \mathrm{g} \mathrm{ml}^{-1}$ ) vancomycin-resistant Staphylococcus aureus (VRSA) isolate that was obtained from a dialysis patient in Michigan, USA, in June 2002. Methicillin-resistant S. aureus (MRSA) and vancomycin-resistant Enterococcus faecalis (VRE) were also isolated from the same patient. The VRSA isolate probably arose after interspecies transfer of a transposon carrying the vanA gene from VRE to a conjugative plasmid in MRSA. 